\title{
Cervical mucus proteome in endometriosis
}

\author{
Giuseppe Grande ${ }^{1}$, Federica Vincenzoni ${ }^{2}$, Domenico Milardi ${ }^{*}$, Giuseppina Pompa ${ }^{1}$, Domenico Ricciardi ${ }^{3}$, \\ Erika Fruscella ${ }^{1}$, Francesca Mancini ${ }^{1}$, Alfredo Pontecorvi ${ }^{4}$, Massimo Castagnola ${ }^{2}$ and Riccardo Marana ${ }^{1,3}$
}

\begin{abstract}
Background: Endometriosis is a chronic gynecological inflammatory disease characterized by the presence of functional endometrial glands and stroma outside of the uterine cavity. It affects $7-10 \%$ of women of reproductive age and up to 50\% of women with infertility. The current gold standard for the diagnosis combines laparoscopic evaluation and biopsy of the visualized lesions. However, laparoscopy requires general anesthesia and developed surgical skills and it has a high procedural cost. In addition, it is associated with the risk, although rare, of potential intraoperative or postoperative complications. To date, several noninvasive biomarkers have been proposed; however, no definite diagnostic biomarker is yet available. The aim of this study was to characterize the CM proteome in patients with endometriosis using high resolution mass spectrometry — based proteomics, implemented by bioinformatic tools for quantitative analysis, in order to investigate the pathophysiological mechanisms of endometriosis.
\end{abstract}

Methods: Cervical mucus samples were collected from patients affected by endometriosis and fertile controls. An aliquot of the soluble acidic fraction of each cervical mucus sample, corresponding to $0.5 \mathrm{mg}$ of total protein, was left to digest with sequencing grade modified porcine trypsin. The peptides were analyzed by LC-MS/MS on a high resolution Orbitrap Elite mass spectrometer and data were evaluated using bioinformatic tools.

Results: We aimed at the first total profiling of the cervical mucus proteome in endometriosis. From the list of identified proteins, we detected a number of differentially expressed proteins, including some functionally significant proteins. Six proteins were quantitatively increased in endometriosis, almost all being involved in the inflammatory pattern. Nine proteins were quantitatively reduced in endometriosis, including some proteins related with local innate immunity (CRISP-3 and Pglyrp1) and protection against oxidative stress (HSPB1). Fifteen proteins were not detected in endometriosis samples including certain proteins involved in antimicrobial activity (SLURP1 and KLK13) and related to seminal plasma liquefaction and male fertility (KLK13).

Conclusions: This is the first application of high resolution mass spectrometry-based proteomics aimed in detecting an array of proteins in CM to be proposed for the noninvasive diagnosis of endometriosis. This chronic disease presents in CM an inflammatory protein pattern.

Keywords: Cervical mucus, Endometriosis, Non-invasive, Markers, Proteomic

\section{Background}

Endometriosis is a chronic gynecological inflammatory disease characterized by the presence of functional endometrial glands and stroma outside of the uterine cavity [1] that affects $7-10 \%$ of women of reproductive age

\footnotetext{
*Correspondence: milardid@yahoo.it

1 International Scientific Institute "Paul VI", L.go F. Vito 1, 00168 Rome, Italy Full list of author information is available at the end of the article
}

and up to $50 \%$ of women with infertility [2]. Many studies report lower fertility rates in women with endometriosis compared to patients free from this disease. Many mechanisms have been suggested to explain the decrease in fertility of these women, such as altered folliculogenesis [3], poor oocyte quality [4], luteal phase defects [5], sperm damage [6], embryo implantation failure [7], abnormal embryogenesis [8]. Studies reported that endometriosis could interfere with the receptivity of eutopic 
endometrium $[9,10]$ and it is associated with abnormal prostaglandin-E2 and cytokine production [11]. Yet, the underlying molecular mechanics that may participate in each of these events is still poorly understood.

Up to $60 \%$ of the women affected by endometriosis present characteristic symptoms such as dysmenorrhea, dyspareunia, dyschezia, dysuria and cyclic back pain, as well as cyclic and noncyclic lower abdominal pain [12]. However, recognition and conclusive diagnosis only occur on the average approximately 9 years following the beginning of the disease [13]. Factors responsible for such a delayed diagnosis include asymptomatic course the of disease, nonspecific symptoms and inconclusive findings in non-invasive examinations. The current gold standard for the diagnosis of the disease combines laparoscopic evaluation and biopsy of the visualized lesions [14]. Although laparoscopy is a minimally invasive procedure, it requires general anesthesia and developed surgical skills, and it has a high procedural cost. In addition, laparoscopy is associated with the risk, although rare, of potential intraoperative or postoperative complications [15].

Early detection would allow individuals affected by the disease more options for treatment, i.e. making earlier surgical treatment more effective and assist in the search for factors involved in pathogenesis. Even though the urgent need for early non-invasive diagnosis was well recognized over a half-century ago [16], no significant contributions to endometriosis diagnosis have been made in this field.

Currently, no non-invasive imaging modalities that can be used to accurately diagnose endometriosis are available in clinical practice.

A recent Cochrane database systematic review [17] concluded that rectosigmoid endometriosis is the only site that could be accurately mapped by using trans-vaginal ultrasound (TVUS), trans-rectal ultrasound (TRUS), magnetic resonance imaging (MRI) or multi-detector computerized tomography enema (MDCT-e). Specifically for endometrioma, TVUS and MRI displayed sufficient accuracy to suggest their utility as a replacement test. However, the data were too scarce to permit meaningful conclusions. Instead of MRI, TVUS could be used clinically to identify additional anatomical sites of deep infiltrating endometriosis, thus facilitating preoperative planning.

To date none of the evaluated imaging modalities is able to detect overall pelvic endometriosis with enough accuracy to be suggested for replacing surgical diagnosis.

To date, several noninvasive biomarkers have been proposed as an adjunct in diagnostics. Cancer antigen 125 (CA 125) is the most widely used biomarker of endometriosis; however, despite the finding of higher CA 125 levels in some women with endometriosis, CA 125 may be a poor biomarker because it does not perform well in the detection of the disease [18]. Diagnostic markers have been searched in peritoneal [19], follicular [20], and endometrial fluid [21], in urine [22], and in blood cells [23] however, no definite diagnostic biomarker is yet available [17].

It is widely accepted that eutopic endometrium from endometriosis patients differ from eutopic endometrium from healthy women. Recent studies reported that matrix metalloproteinase-2 (MMP-2), MMP-9, tissue inhibitor of matrix metalloproteinases (TIMP-1) and transforming growth factor- $\beta 2$ (TGF- $\beta 2$ ) express a tendency to higher gene expression in the eutopic endometrium of women with endometriosis [24]. Euctopic endometrioum from endometriosis patients expresses moreover different miRNA profiles [25] and an aberrant DNA methylome [26].

In addition, because implants of endometriosis in the pelvic cavity release substances in the peritoneal fluid that bathe the ovary and enter the uterine cavity through the oviducts, endometriotic markers may influence the entire reproductive system, including the cervical mucus (CM). No studies have been performed up to now to verify the possibility of identifying non-invasive biomarkers of endometriosis in CM.

The development of high-throughput technologies, such as proteomics, has led to an early identification of the diseases by comparing the protein composition in diseased and normal tissues [27]. In a previous study we confirmed that CM is a source of protein biomarkes and identified the constitutive protein composition of $\mathrm{CM}$ of fertile women and the changes in the CM proteome throughout the menstrual cycle [28].

The aim of this study was to characterize the pattern of proteins involved in the pathophysiology of endometriosis. This aim could be important to furtherly focus which of these proteins could represent putative markers of endometriosis in CM.

\section{Methods \\ Study design}

Ten 30-40 year old infertile women, with ovarian endometriotic cysts were enrolled. Ten fertile women, with no history of fertility problems and who had a term delivery within 1 year before the study served as control group.

The inclusion criterion was a maximum age of 40 years for both groups. A specific inclusion criterion for the patients with endometriosis was that the endometriosis diagnosis was obtained by videolaparoscopy and confirmed by histological exam of the endometiotic cyst.

The exclusion criteria for both groups were as follows: patients with a history of polycystic ovary syndrome, cancer, premature ovarian failure, or other 
gynecologic factors leading to infertility that could affect folliculogenesis.

Cervical and vaginal swabs were obtained before sample collection to exclude cervical and vaginal infection. PAP tests and colposcopy were also performed before sample collection.

\section{CM collection and sample preparation}

Cervical mucus samples ( $\mathrm{n}=1$ per patient) were obtained by gentle aspiration from the cervical canal using a catheter for intrauterine insemination (Gynetics Medical Products, Achel, Belgium). Samples were collected during the ovulation phase of the menstrual cycle. Ovulation was assessed by transvaginal sonography and confirmed by the measurement of midluteal serum progesterone levels.

The cervical mucus was collected in plastic tubes and mixed 1:1 (v/v) with aqueous trifluoroacetic acid solution $(0.2 \% \mathrm{v} / \mathrm{v})$ and centrifuged at $9200 \mathrm{~g}$ for $10 \mathrm{~min}$. The soluble acidic fraction was stored at $-80{ }^{\circ} \mathrm{C}$ until analysis. An aliquot of the soluble acidic fraction of each CM sample, corresponding to $40 \mu \mathrm{g}$ of total protein (as measured by the Bradford assay), was mixed with $1 \mathrm{M}$ ammonium bicarbonate $\mathrm{pH} 8.0$ and reduced with $200 \mathrm{mM}$ dithiothreitol (DTT $10 \mathrm{mM}$ final, Sigma) for $5 \mathrm{~min}$ at $100{ }^{\circ} \mathrm{C}$ and $15 \mathrm{~min}$ at $50{ }^{\circ} \mathrm{C}$, and then alkylated with $200 \mathrm{mM}$ iodoacetamide (IAA $55 \mathrm{mM}$ final, Sigma) in the dark at room temperature for $60 \mathrm{~min}$. The samples were left to digest overnight at $37^{\circ} \mathrm{C}$ by adding $100 \mathrm{mM}$ ammonium bicarbonate $(\mathrm{pH} 8)$ with sequencing grade modified porcine trypsin (1:50, trypsin:protein concentration, Pierce Biotechnology). To stop the digestion, the samples were acidified with aqueous trifluoroacetic acid solution $(0.2 \%$ $\mathrm{v} / \mathrm{v}$ ) and immediately frozen and lyophilized.

\section{Proteomic analysis}

The samples were resuspended in $40 \mu \mathrm{l}$ of aqueous formic acid solution $(0.1 \% \mathrm{v} / \mathrm{v})$ and equal protein quantity $(8 \mu \mathrm{g})$ of each sample was analyzed using an Ultimate 3000 RSLCnano equipped with an FLM-3000-Flow manager module, and coupled using an Orbitrap Elite mass spectrometer (ThermoFisher, San Jose, CA). Separation experiments were performed using a Zorbax 300SB-C18 column (3.5 mm particle diameter; column dimension $1 \mathrm{~mm}$ i.d. $15 \mathrm{~cm}$ ) (Agilent Technologies, Santa Clara, CA) using the following eluents: (A) $0.1 \%(\mathrm{v} / \mathrm{v})$ aqueous formic acid and (B) acetonitrile:water 80:20 with $0.1 \%(\mathrm{v} / \mathrm{v})$ aqueous formic acid. The applied gradient was linear from 0 to $55 \%$ of solvent B in $60 \mathrm{~min}$, at a flow rate of $50 \mu \mathrm{l} / \mathrm{min}$. The Elite-Orbitrap mass spectrometer was operated in data-dependent mode in which each full MS scan (60 000 resolving power) was followed by MS/MS scans where the five most intense multiple-charged ions were dynamically selected and fragmented by collision-induced dissociation (CID) at a normalized collision energy of 35\%. Samples were analyzed individually; proteomic analysis was performed at the same time for all samples, while data analysis was subsequently performed.

\section{Data analysis}

Tandem mass spectra were analysed using the Thermo Proteome Discoverer 1.4 software, and the SEQUEST cluster (University of Washington, Seattle, WA, licensed by Thermo Electron Corp) as the search engine against UniProtKb/Swiss-Prot protein knowledgebase release 2015-10: 20196 Homo Sapiens protein database.

In order to obtain a reliable identification of the peptides, the following filters were used: high value peptide confidence and false discovery rate (FDR) of $5 \%$.

Data were searched for three missed cleavages, fixed carbamidomethylation of cysteines and the oxidation of methionines as variable modification.

The label-free quantification of common proteins was performed via Precursor Ions Area Detector Node during the bioinformatic analysis using Proteome Discoverer software. This quantification method was used to obtain an idea of the relative quantities of all peptides in a sample. The Proteome Discoverer application calculates peptide areas during processing, using them to automatically calculate protein areas for the proteins in the report. It calculates the area of any given protein as the average of the three most abundant distinct peptides identified in the protein.

Results are reported as average \pm standard deviation. Statistical analysis was carried out with SPSS v17.0 (IBM Corp., Armonk,NY, USA). All data were first analyzed for normality of distribution using the KolmogorovSmirnov test of Normality. Since data were not normally distributed, the appropriate non-parametric (MannWhitney) test was used to assess significance of the differences between groups. $p$ value $<0.05$ was considered as significant.

For the aim of this study, we considered the panel of proteins exclusively identified in the endometriosis group and in the control group. Moreover we evaluated the proteins significantly increased or reduced according to abundance index in the endometriosis versus the control group.

\section{Results}

Protein identification led to the characterization of a range of 44-140 different proteins per sample in the endometriosis group and 91-126 proteins in the control group.

All the proteins we identified in the endometriosis group have been detected in the control group. 
Six proteins were quantitatively increased in endometriosis, as reported in Fig. 1 and almost all are involved in the inflammatory pattern.

Nine proteins were quantitatively reduced in endometriosis, as reported in Fig. 2, including some proteins related with local innate immunity (CRISP-3 and Pglyrp1) and protection against oxidative stress (HSPB1).

Additional file 1: Table S1 reports the identified proteins in the two groups.

Table 1 reports the mean values of the abundance index for each protein in the two groups, the number of samples in which the proteins have been detected in patients and controls and if the protein was or not previously reported as a marker of endometriosis.

Fifteen proteins were not detected in endometriosis samples compared to controls (Table 2) including some proteins involved in antimicrobial activity (SLURP1 and KLK13) or previously reported as related to seminal plasma liquefaction and male fertility (KLK13).

\section{Discussion}

In the postgenomic era, proteomic technology has rapidly developed and it has become a powerful tool in the research of human physiology, in particular in biological fluids, characterizing the comprehensive proteomic composition and identifying potential novel biomarkers for diagnosis, prognosis and therapy in different clinical aspects, including reproduction [29]. Cervical mucus is a biofluid, representing a source of putative biomarkers for female genital tract diseases. The proteomic composition of cervical mucus is less complex when compared to plasma and urine, but few studies investigated cervical mucus composition in physiological conditions [28, 30] and no studies have been reported up to now concerning the identification of $\mathrm{CM}$ biomarkers for genital tract diseases.

We studied for the first time CM protein composition with the aim of identifying some proteins involved in the pathophysiology of endometriosis. The integration of high-resolution MS proteomic techniques and bioinformatic analysis permitted the identification of a pattern of proteins which could represent a molecular signature of endometriosis.

\section{Overexpressed proteins}

Six proteins resulted overexpressed in endometriosis: 4 out to these 6 proteins are related with inflammation, including polymeric immunoglobulin receptor (pIgR), Alpha-1-acid glycoprotein 2, Metalloproteinase inhibitor 1 and Neutrophil gelatinase-associated lipocalin. Inflammatory processes have a crucial role in the pathogenesis of endometriosis [31] as suggested by the abnormal

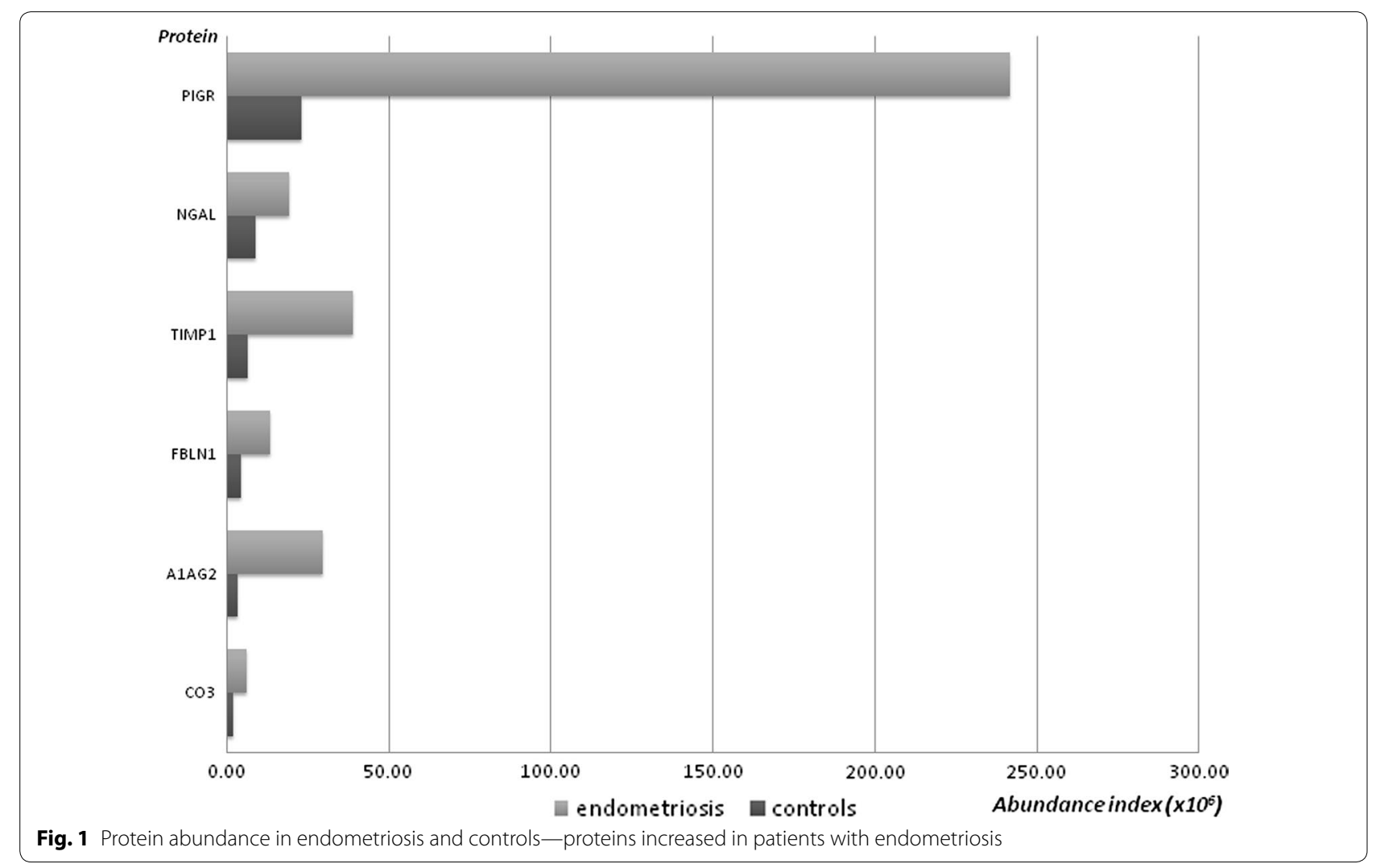




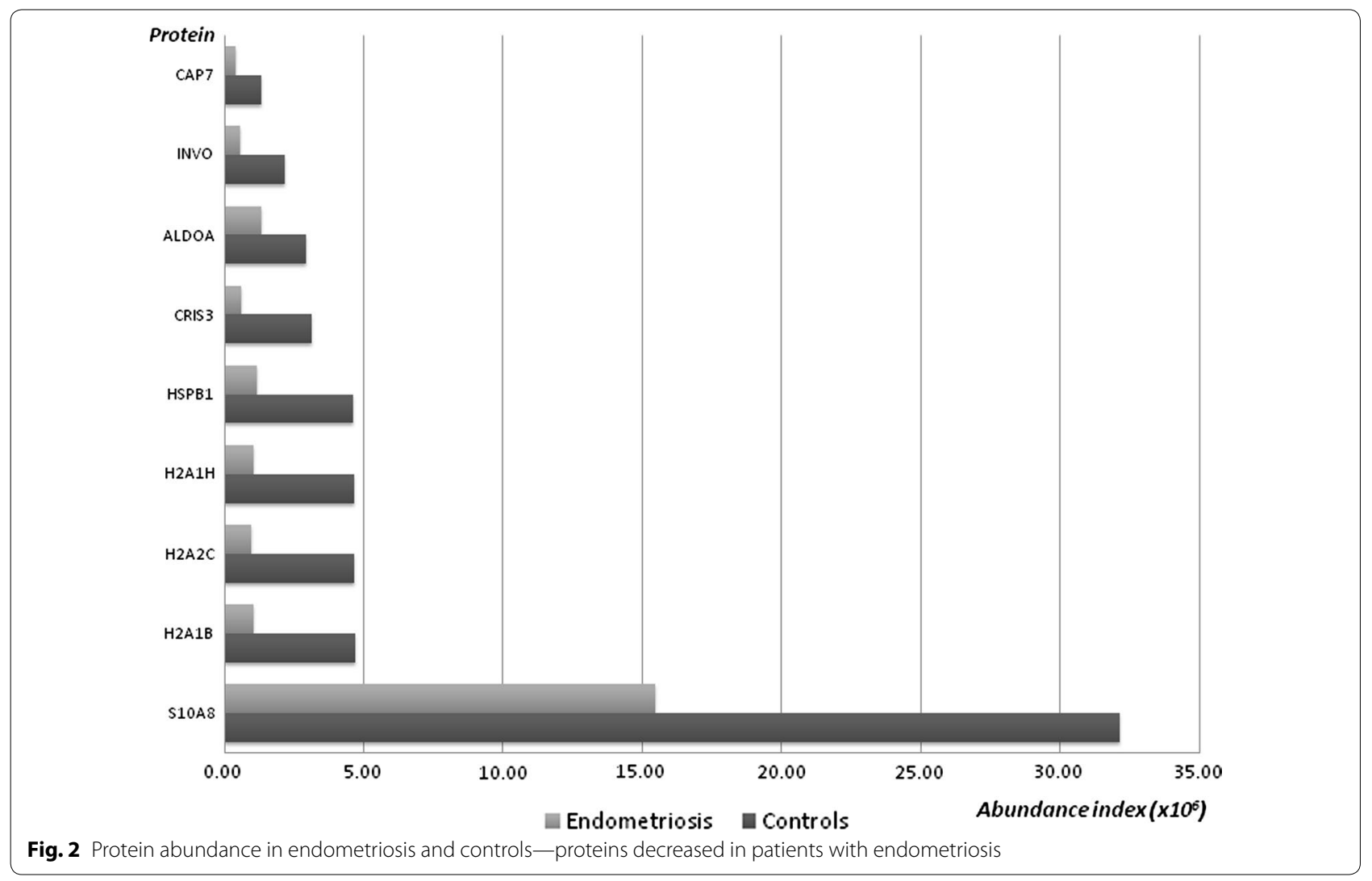

levels of immune system cells, including macrophages [32], dendritic cells [33] and natural killer cells [34], within the female reproductive tract reported in patients with endometriosis. These cells are unable to completely eliminate ectopic endometrial cells. Moreover, immune system cells were found to be dysfunctional in endometriosis [34, 35]. Complicated reactions may occur due to endometriosis-induced secretion of cytokines [36], chemokines [37], nitric oxide [38], immunoglobulins [39], and immune cells [32-35]. Triggered immune reactions signify the host recognition of infectious agents, but, if pathogens are not swiftly recognized, immune reactions necessary to fight infections do not occur. Previous data reported an higher prevalence of endometritis in women with endometriosis [40], which may represent an adjunctive mechanisms to explain the decrease of fertility in these women.

The overexpressed proteins verified in this study confirm the presence of inflammatory protein pattern in CM of patients with endometriosis, even if vaginal and cervical swabs excluded vaginal and cervical infection in all patients.

In particular, Polimeric Immunoglobulin Receptor (pIgR) plays an important role in mucosal immune systems, since it binds and transports $\operatorname{IgA}$ in different mucosal tissues [41]. Previous data reported that IgA and IgG are differentially associated with the types of mucus of the female reproductive tract, since both IgA and IgG are stably associated with cervical mucus, but only IgG is associated with cervicovaginal mucus [42]. Antibodies can bind tightly to mucus, where they play a significant role in the fortification of the mucus barriers of the female reproductive tract.

Orosomucoid 2 (ORM2), also known as alpha 1 acid glycoprotein 2 , is a type of acute-phase protein considered an anti-inflammatory and immunomodulatory factor due to its anti-neutrophil and anti-complement activity [43].

Tissue inhibitors of metalloproteinases (TIMP) are the inhibitors of matrix metalloproteinases. Expression of matrix metalloproteinases (MMPs) and their inhibitors (tissue inhibitors of metalloproteinases, TIMPs) is reportedly involved in the pathogenesis and pathophysiology of endometriosis. The MMPs and TIMPs are synthesized and secreted by both eutopic and ectopic endometrium in both the human and the rat $[44,45]$. TIMP1 represents at least $10-15 \%$ of the proteins secreted into the peritoneal cavity by both rat implants and human endometriotic lesions [46]. Previous data reported that an excessive TIMP1 secretion in endometriosis was deleterious to 


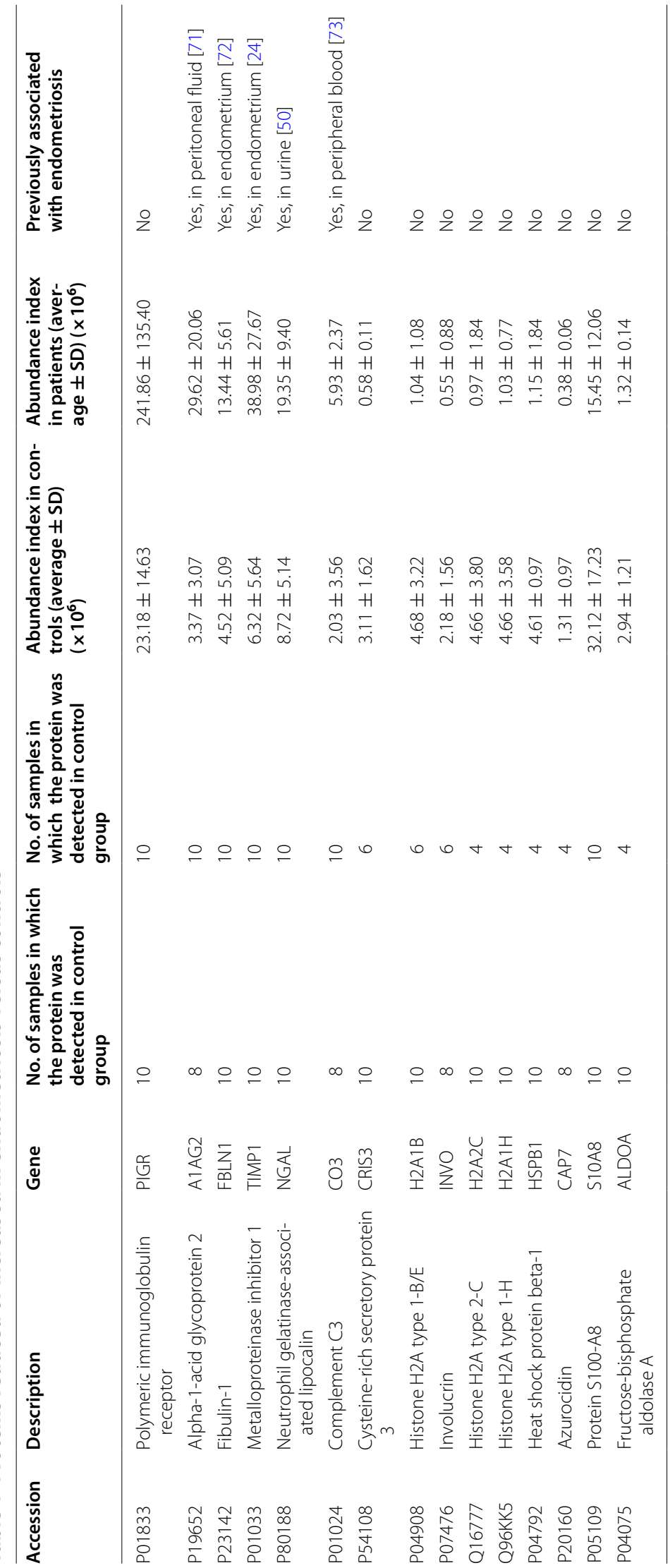


Table 2 Proteins not detected in CM of patients with endometriosis

\begin{tabular}{|c|c|c|c|c|c|c|c|c|c|}
\hline Accession & Description & $\Sigma$ coverage & $\Sigma \#$ proteins & $\begin{array}{l}\Sigma \# \text { unique } \\
\text { peptides }\end{array}$ & $\Sigma \#$ peptides & $\begin{array}{l}\text { No. of samples } \\
\text { the protein } \\
\text { was detected } \\
\text { in the control } \\
\text { group }\end{array}$ & MW (kDa) & X score (mean) & Calc.pl \\
\hline P01040 & Cystatin-A & 70.41 & 1 & 5 & 5 & 8 & 11.0 & 15.01 & 5.50 \\
\hline P55000 & $\begin{array}{l}\text { Secreted Ly-6/ } \\
\text { uPAR-related } \\
\text { protein } 1\end{array}$ & 52.43 & 1 & 2 & 2 & 8 & 11.2 & 12.88 & 5.33 \\
\hline Q9UKR3 & Kallikrein-13 & 36.10 & 1 & 6 & 6 & 10 & 30.6 & 18.10 & 8.46 \\
\hline O75594 & $\begin{array}{l}\text { Peptidoglycan } \\
\text { recognition } \\
\text { protein } 1\end{array}$ & 26.53 & 1 & 3 & 3 & 8 & 21.7 & 11.65 & 8.59 \\
\hline P02671 & $\begin{array}{l}\text { Fibrinogen alpha } \\
\text { chain }\end{array}$ & 24.71 & 1 & 12 & 12 & 8 & 94.9 & 26.72 & 6.01 \\
\hline P10153 & $\begin{array}{c}\text { Non-secretory } \\
\text { ribonuclease }\end{array}$ & 22.98 & 1 & 4 & 4 & 8 & 18.3 & 11.93 & 8.73 \\
\hline O95274 & $\begin{array}{l}\text { Ly6/PLAUR } \\
\text { domain- } \\
\text { containing } \\
\text { protein } 3\end{array}$ & 21.97 & 1 & 4 & 4 & 10 & 35.9 & 25.57 & 7.75 \\
\hline P12724 & $\begin{array}{l}\text { Eosinophil cati- } \\
\text { onic protein }\end{array}$ & 20.00 & 1 & 3 & 3 & 8 & 18.4 & 13.78 & 10.02 \\
\hline P52566 & $\begin{array}{l}\text { Rho GDP- } \\
\text { dissociation } \\
\text { inhibitor } 2\end{array}$ & 19.90 & 1 & 3 & 3 & 8 & 23.0 & 9.13 & 5.21 \\
\hline O75015 & $\begin{array}{l}\text { Low affinity } \\
\text { immunoglob- } \\
\text { ulin gamma FC } \\
\text { region recep- } \\
\text { tor III-B }\end{array}$ & 19.31 & 1 & 3 & 3 & 8 & 26.2 & 11.20 & 6.71 \\
\hline P00338 & $\begin{array}{l}\text { L-lactate dehy- } \\
\text { drogenase A } \\
\text { chain }\end{array}$ & 14.76 & 1 & 3 & 3 & 8 & 36.7 & 9.94 & 8.27 \\
\hline P32926 & Desmoglein-3 & 10.01 & 1 & 7 & 7 & 8 & 107.5 & 43.29 & 5.00 \\
\hline Q02487 & Desmocollin-2 & 8.88 & 1 & 4 & 4 & 8 & 99.9 & 29.56 & 5.34 \\
\hline P07477 & Trypsin-1 & 7.29 & 1 & 2 & 2 & 9 & 26.5 & 7.55 & 6.51 \\
\hline POCOL4 & $\begin{array}{l}\text { Complement } \\
\text { C4-A }\end{array}$ & 1.95 & 2 & 2 & 2 & 9 & 192.7 & 9.55 & 7.08 \\
\hline
\end{tabular}

ovulation and embryo development [47]. There are some literature reports about the expression of TIMP in CM, linking the expression of metalloproteinases-TIMP systems in the cervical mucus plug during pregnancy with the proteolytic activity in connection with term and preterm birth [48]. We previously reported that TIMP-1 is a marker of pre-ovulatory $\mathrm{CM}$ in fertile patients that might be associated with the inhibition of proteolitic activity, which leads to the liquefaction of CM in the ovulatory phase [28]. In patients with endometriosis, the higher expression of TIMP-1 during ovulatory phase might contribute in inhibiting the proteolitic activity and the liquefaction of CM, which is essential for CM permeability to spermatozoa.
Neutrophil gelatinase-associated lipocalin (NGAL) was previously identified by a proteomic approach as a marker of neutrophil activity in cervical-vaginal fluid [49]. NGAL has been previously reported to be elevated in the urine of patients with endometriosis [50].

In conclusion, the proteic pattern of abacterial cervical inflammation associated with endometriosis might both reflect the dysfunctional immune pattern of endometriosis and represent a link with endometriosis-associated infertility.

\section{Down-expressed proteins in endometriosis}

Nine proteins were reduced in endometriosis, including Azurocidin 1, an important inflammatory mediator [51], 
cysteine-rich secretory protein 3 (CRISP-3) and Heat shock protein beta-1 (HSPB1).

CRISP-3 is present in exocrine secretions and in secretory granules of neutrophilic granulocytes and is believed to play a role in local innate immunity, which is depressed in patients with endometriosis [52]. Furthermore CRISP proteins have been reported to exert a role in spermoocyte chemotaxis both in frogs and mouse [53].

We observed a reduction of the antioxidant protein HSPB1. It is a small heat shock protein involved in many cellular processes, which protects cells against oxidative stress [54]. Endometriosis has been previously reported to be linked with oxidative stress, altering follicular microenvironment and oocyte quality $[55,56]$. Further studies will clarify if endometriosis is associated with oxidative stress pattern in cervical mucus and its correlation with female infertility.

\section{Proteins not detected in endometriosis samples}

Fifteen proteins were not detected in endometriosis samples, including some proteins involved in antimicrobial activity and possibly associated with fertility.

Human tissue kallikreins are members of a large multigene family of 15 serine proteases. The human kallikrein 13 gene (KLK13) codes for a trypsin-like, secreted serine protease (hK13). It was reported to be expressed in various tissues [57] and found at high concentrations in secreted biological fluids such as seminal plasma, amniotic fluid, milk of lactating women, follicular fluid, and cerebrospinal fluid [58], but up to now not reported as expressed in cervical mucus. Previous studies reported that kallikreins are important in the control of sperm liquefaction and sperm motility [59]. Further studies are needed to clarify the functional role of hK13 in cervical mucus and the molecular significance of its absence in endometriosis. We may speculate that the absence KLK13 in endometriosis could have a role in infertility.

We observed the absence of secreted Ly6/urokinasetype plasminogen activator receptor-related protein (SLURP) 1 and 3 proteins. SLURP1 belongs to the Ly6/ uPAR superfamily of proteins that participate in signal transduction, immune activation, and cell adhesion [60]. It is expressed in a variety of cells including immune cells [61], bronchial epithelial cells [62], primary sensory neurons [63], skin, gums, stomach, trachea and esophagus [64], oral keratinocytes [65], cornea [66] and exocervix [64]. In corneal tissue it was reported that SLURP1 is a soluble scavenger of urokinase-type plasminogen activator (UPAR) and of its soluble form (suPAR) [67]. Numerous studies have shown that systemic soluble urokinase plasminogen activator receptor (suPAR) levels increase in various inflammatory diseases. In recent years it has been considered a reliable diagnostic and prognostic marker of systemic inflammation. uPAR and its ligand are involved in numerous physiological and pathological pathways, which include the plasminogen activating pathway, regulation of pericellular proteolysis, modulation of cell adhesion, migration, and proliferation through interactions with proteins present in the extracellular matrix [68]. In a previous study we demonstrated that suPAR might represent an inflammatory marker in reproduction for the male accessory glands [69]. In cervical mucus of patients with endometriosis we reported the absence of the scavenger proteins SLURP-1 and SLURP-3. We may speculate that endometriosis might cause an increase in uPAR activation and suPAR production, which are associated with an inflammatory pattern. Further studies are needed to confirm these data.

In $\mathrm{CM}$ of patients with endometriosis we reported the differential expression of Peptidoglycan recognition protein 1 (Pglyrp1). Pglyrps are a family of pattern-recognition proteins that mediate innate immunity to bacterial pathogens via binding peptidoglycan moieties [70]. Previous literature data confirmed that subclinical uterine infection and endometritis are more frequent in women with endometriosis versus controls [40]. The absence of Pglyrp1 might represent a molecular mechanism involved in the higher prevalence of infections in patients with endometriosis.

\section{Conclusions}

We identified in the $\mathrm{CM}$ of patients affected by endometriosis some proteins which are mainly related to the pathogenesis of inflammation and the induction of a dysfunctional immune system. These data are consistent with previous reports about endometriosis as a chronic inflammatory disease.

Despite the limitations of the study, which was performed using fertile women and not on patients with endometriosis-like symtoms, without endometriosis at laparoscopic and histological examination, as control group, this is the first application of high resolution mass spectrometry-based proteomics aimed to reveal an array of proteins in $\mathrm{CM}$ which might represent a molecular signature of endometriosis. Our data confirm at the same time both the inflammatory pattern and the impairment of the natural immune system in the $\mathrm{CM}$ of patients affected by endometriosis.

\section{Additional file}

Additional file 1: Table S1. Identified proteins in CM in the group of controls and in patients affected by endometriosis. 


\section{Authors' contributions}

GG made substantial contributions to conception and design of the study and to the interpretation of data, was involved in drafting the manuscript, gave final approval of the version to be published and agreed to be accountable for all aspects of the work in ensuring that questions related to the accuracy or integrity of any part of the work are appropriately investigated and resolved; FV made substantial contributions to acquisition and analysis of data, was involved in drafting the manuscript, gave final approval of the version to be published and agreed to be accountable for all aspects of the work in ensuring that questions related to the accuracy or integrity of any part of the work are appropriately investigated and resolved; DM made substantial contributions to conception and design of the study, was involved in drafting the manuscript, gave final approval of the version to be published and agreed to be accountable for all aspects of the work in ensuring that questions related to the accuracy or integrity of any part of the work are appropriately investigated and resolved; GP made substantial contributions to conception and design of the study, was involved in critically revising the manuscript for important intellectual content, gave final approval of the version to be published and agreed to be accountable for all aspects of the work in ensuring that questions related to the accuracy or integrity of any part of the work are appropriately investigated and resolved; DR made substantial contributions to the acquisition of data, was involved in critically revising the manuscript for important intellectual content, gave final approval of the version to be published and agreed to be accountable for all aspects of the work in ensuring that questions related to the accuracy or integrity of any part of the work are appropriately investigated and resolved; EF made substantial contributions to the acquisition of data, was involved in critically revising the manuscript for important intellectual content, gave final approval of the version to be published and agreed to be accountable for all aspects of the work in ensuring that questions related to the accuracy or integrity of any part of the work are appropriately investigated and resolved; FM made substantial contributions to acquisition and analysis of data, was involved in critically revising the manuscript for important intellectual content, gave final approval of the version to be published and agreed to be accountable for all aspects of the work in ensuring that questions related to the accuracy or integrity of any part of the work are appropriately investigated and resolved; AP made substantial contributions to conception and design of the study, was involved in critically revising the manuscript for important intellectual content, gave final approval of the version to be published and agreed to be accountable for all aspects of the work in ensuring that questions related to the accuracy or integrity of any part of the work are appropriately investigated and resolved; MC made substantial contributions to conception and design of the study, was involved in critically revising the manuscript for important intellectual content, gave final approval of the version to be published and agreed to be accountable for all aspects of the work in ensuring that questions related to the accuracy or integrity of any part of the work are appropriately investigated and resolved; RM made substantial contributions to conception and design of the study, was involved in critically revising the manuscript for important intellectual content, gave final approval of the version to be published and agreed to be accountable for all aspects of the work in ensuring that questions related to the accuracy or integrity of any part of the work are appropriately investigated and resolved. All authors read and approved the final manuscript.

\section{Author details}

1 International Scientific Institute "Paul VI", L.go F. Vito 1, 00168 Rome, Italy. ${ }^{2}$ Institute of Biochemistry and Clinical Biochemistry, Catholic University, L.go F. Vito 1, 00168 Rome, Italy. ${ }^{3}$ Department of Obstetrics and Gynecology, Fondazione Policlinico Universitario A. Gemelli, L.go F. Vito 1, 00168 Rome, Italy. ${ }^{4}$ Division of Endocrinology, Catholic University, L.go F. Vito 1, 00168 Rome, taly.

\section{Acknowledgements}

The authors thank Claudia Menaldino (New York, USA) for her kind and careful English editing.

\section{Competing interests}

The authors declare that they have no competing interests.

\section{Availability of data and materials}

The datasets during and/or analysed during the current study available from the corresponding author on reasonable request.

\section{Ethics approval and consent to participate}

The design of the study was approved by the Institutional Review Board of our University. All the participants gave informed consent according to the guidelines of the Declaration of Helsinki. The datasets during and/or analysed during the current study available from the corresponding author on reasonable request.

\section{Funding}

The project was completely founded by Institutional sources (International Scientific Institute "Paul VI", Rome).

Received: 2 August 2016 Accepted: 25 January 2017

Published online: 02 February 2017

\section{References}

1. Giudice LC, Kao LC. Endometriosis. Lancet. 2004;364(9447):1789-99.

2. Marana R, Lecca A, Biscione A, Muzii L. Endometriosis: the gynecologist's opinion. Urologia. 2012;79(3):160-6.

3. Doody MC, Gibbons WE, Buttram VC Jr. Linear regression analysis of ultrasound follicular growth series: evidence for an abnormality of follicular growth in endometriosis patients. Fertil Steril. 1988;49(1):47-51.

4. Da Broi MG, Navarro PA. Oxidative stress and oocyte quality: ethiopathogenic mechanisms of minimal/mild endometriosis-related infertility. Cell Tissue Res. 2016;364(1):1-7.

5. Matorras R, Rodríguez F, Pérez C, Pijoan Jl, Neyro JL, Rodríguez-Escudero FJ. Infertile women with and without endometriosis: a case control study of luteal phase and other infertility conditions. Acta Obstet Gynecol Scand. 1996;75(9):826-31.

6. Carli C, Leclerc P, Metz CN, Akoum A. Direct effect of macrophage migration inhibitory factor on sperm function: possible involvement in endometriosis-associated infertility. Fertil Steril. 2007;88(4 Suppl):1240-7.

7. Brosens JJ, Hodgetts A, Feroze-Zaidi F, Sherwin JR, Fusi L, Salker MS, et al. Proteomic analysis of endometrium from fertile and infertile patients suggests a role for apolipoprotein A-I in embryo implantation failure and endometriosis. Mol Hum Reprod. 2010;16(4):273-85.

8. Brizek CL, Schlaff S, Pellegrini VA, Frank JB, Worrilow KC. Increased incidence of aberrant morphological phenotypes in human embryogenesis - an association with endometriosis. J Assist Reprod Genet. 1995; 12(2):106-12.

9. Tiberi F, Tropea A, Romani F, Apa R, Marana R, Lanzone A. Prokineticin 1, homeobox A10, and progesterone receptor messenger ribonucleic acid expression in primary cultures of endometrial stromal cells isolated from endometrium of healthy women and from eutopic endometrium of women with endometriosis. Fertil Steril. 2010;94(7):2558-63.

10. Tiberi F, Tropea A, Apa R, Romani F, Lanzone A, Marana R. Prokineticin 1 mRNA expression in the endometrium of healthy women and in the eutopic endometrium of women with endometriosis. Fertil Steril. 2010;93(7):2145-9.

11. Minici F, Tiberi F, Tropea A, Orlando M, Gangale MF, Romani F, et al. Endometriosis and human infertility: a new investigation into the role of eutopic endometrium. Hum Reprod. 2008;23(3):530-7.

12. Nnoaham KE, Hummelshoj L, Kennedy SH, Jenkinson C, Zondervan KT. Developing symptom-based predictive models of endometriosis as a clinical screening tool: results from a multicenter study. Fertil Steril. 2012;98(3):670-92.

13. Luisi S, Lazzeri L, Ciani V, Petraglia F. Endometriosis in Italy: from cost estimates to new medical treatment. Gynecol Endocrinol. 2009;25(11):734-40.

14. Kennedy S, Bergqvist A, Chapron C, D'Hooghe T, Dunselman G, Greb R, et al. ESHRE guideline for the diagnosis and treatment of endometriosis. Hum Reprod. 2005;20:2698-704.

15. Karaman Y, Uslu H. Complications and their management in endometriosis surgery. Womens Health. 2015;11(5):685-92.

16. Greene $\mathrm{EH}$. Endometriosis: the urgency for early diagnosis and treatment J Med Assoc Ga. 1950;39(7):283-6.

17. Nisenblat V, Bossuyt PM, Farquhar C, Johnson N, Hull ML. Imaging modalities for the non-invasive diagnosis of endometriosis. Cochrane Database Syst Rev. 2016;2:CD009591. 
18. Nisenblat V, Bossuyt PM, Shaikh R, Farquhar C, Jordan V, Scheffers CS, et al. Blood biomarkers for the non-invasive diagnosis of endometriosis. Cochrane Database Syst Rev. 2016;5:CD012179.

19. Rižner TL. Diagnostic potential of peritoneal fluid biomarkers of endometriosis. Expert Rev Mol Diagn. 2015;15(4):557-80.

20. Prieto L, Quesada JF, Cambero O, Pacheco A, Pellicer A, Codoceo R, et al. Analysis of follicular fluid and serum markers of oxidative stress in women with infertility related to endometriosis. Fertil Steril. 2012;98(1):126-30.

21. Ametzazurra A, Matorras R, García-Velasco JA, Prieto B, Simón L, Martínez $A$, et al. Endometrial fluid is a specific and non-invasive biological sample for protein biomarker identification in endometriosis. Hum Reprod. 2009;24(4):954-65.

22. Liu E, Nisenblat V, Farquhar C, Fraser I, Bossuyt PM, Johnson N, Hull ML. Urinary biomarkers for the non-invasive diagnosis of endometriosis. Cochrane Database Syst Rev. 2015;12:CD012019.

23. Cho S, Cho H, Nam A, Kim HY, Choi YS, Park KH, et al. Neutrophil-to-lymphocyte ratio as an adjunct to CA-125 for the diagnosis of endometriosis. Fertil Steril. 2008;90(6):2073-9.

24. Szymanowski K, Mikołajczyk M, Wirstlein P, Dera-Szymanowska A. Matrix metalloproteinase-2 (MMP-2), MMP-9, tissue inhibitor of matrix metalloproteinases (TIMP-1) and transforming growth factor- $\beta 2$ (TGF- $\beta 2$ ) expression in eutopic endometrium of women with peritoneal endometriosis. Ann Agric Environ Med. 2016;23(4):649-53.

25. Nothnick WB, Falcone T, Joshi N, Fazleabas AT, Graham A. Serum miR-451a levels are significantly elevated in women with endometriosis and recapitulated in baboons (Papio anubis) with experimentally-induced disease. Reprod Sci. 2016. doi:10.1177/1933719116681519.

26. Houshdaran S, Nezhat CR, Vo KC, Zelenko Z, Irwin JC, Giudice LC. Aberrant endometrial DNA methylome and associated gene expression in women with endometriosis. Biol Reprod. 2016;95(5):93.

27. Ghafourian S, Sekawi Z, Raftari M, Ali MS. Application of proteomics in lab diagnosis. Clin Lab. 2013;59(5-6):465-74.

28. Grande G, Milardi D, Vincenzoni F, Pompa G, Biscione A, Astorri AL, et al. Proteomic characterization of the qualitative and quantitative differences in cervical mucus composition during the menstrual cycle. Mol BioSyst. 2015;11(6):1717-25.

29. Milardi D, Grande G, Vincenzoni F, Castagnola M, Marana R. Proteomics of human seminal plasma: identification of biomarker candidates for fertility and infertility and the evolution of technology. Mol Reprod Dev. 2013;80(5):350-7.

30. Brunelli R, Papi M, Arcovito G, Bompiani A, Castagnola M, Parasassi T, et al. Globular structure of human ovulatory cervical mucus. FASEB J. 2007;21(14):3872-6.

31. Jiang $L$, Yan Y, Liu Z, Wang Y. Inflammation and endometriosis. Front Biosci. 2016;21:941-8.

32. Takebayashi A, Kimura F, Kishi Y, Ishida M, Takahashi A, Yamanaka A, et al. Subpopulations of macrophages within eutopic endometrium of endometriosis patients. Am J Reprod Immunol. 2015;73(3):221-31.

33. Schulke L, Berbic M, Manconi F, Tokushige N, Markham R, Fraser IS. Dendritic cell populations in the eutopic and ectopic endometrium of women with endometriosis. Hum Reprod. 2009;24(7):1695-703.

34. Thiruchelvam U, Wingfield M, O'Farrelly C. Natural killer cells: key players in endometriosis. Am J Reprod Immunol. 2015;74(4):291-301.

35. Braun DP, Dmowski WP. Endometriosis: abnormal endometrium and dysfunctional immune response. Curr Opin Obstet Gynecol. 1998;10(5):365-9.

36. Rakhila H, Al-Akoum M, Bergeron ME, Leboeuf M, Lemyre M, Akoum A, et al. Promotion of angiogenesis and proliferation cytokines patterns in peritoneal fluid from women with endometriosis. J Reprod Immunol. 2016;1 16:1-6.

37. Borrelli GM, Carvalho KI, Kallas EG, Mechsner S, Baracat EC, Abrão MS. Chemokines in the pathogenesis of endometriosis and infertility. J Reprod Immunol. 2013;98(1-2):1-9.

38. Yeo SG, Won YS, Lee HY, Kim YI, Lee JW, Park DC. Increased expression of pattern recognition receptors and nitric oxide synthase in patients with endometriosis. Int J Med Sci. 2013;10(9):1199-208.

39. Badawy SZ, Cuenca V, Kaufman L, Stitzel A, Thompson M. The regulation of immunoglobulin production by B cells in patients with endometriosis. Fertil Steril. 1989;51(5):770-3.

40. Takebayashi A, Kimura F, Kishi Y, Ishida M, Takahashi A, Yamanaka A, et al. The association between endometriosis and chronic endometritis. PLoS ONE. 2014;9(2):e88354.
41. Johansen FE, Kaetzel CS. Regulation of the polymeric immunoglobulin receptor and IgA transport: new advances in environmental factors that stimulate plgR expression and its role in mucosal immunity. Mucosal Immunol. 2011;4(6):598-602.

42. Fahrbach KM, Malykhina O, Stieh DJ, Hope TJ. Differential binding of $\lg G$ and $\lg A$ to mucus of the female reproductive tract. PLOS ONE. 2013;8(10):e76176.

43. Luo Z, Lei H, Sun Y, Liu X, Su DF. Orosomucoid, an acute response protein with multiple modulating activities. J Physiol Biochem. 2015;71 (2):329-40.

44. Gilabert-Estellés J, Ramón LA, España F, Gilabert J, Vila V, Réganon E, et al. Expression of angiogenic factors in endometriosis: relationship to fibrinolytic and metalloproteinase systems. Hum Reprod. 2007;22(8):2120-7.

45. Sharpe-Timms KL, Penney LL, Zimmer RL, Wright JA, Zhang Y, Surewicz K. Partial purification and amino acid sequence analysis of endometriosis protein-II (ENDO-II) reveals homology with tissue inhibitor of metalloproteinases-1 (TIMP-1). J Clin Endocrinol Metab. 1995;80(12):3784-7.

46. Sharpe KL, Zimmer RL, Griffin WT, Penney LL. Polypeptides synthesized and released by human endometriosis differ from those of the uterine endometrium in cell and tissue explant culture. Fertil Steril. 1993;60:839-51.

47. Stilley JA, Birt JA, Nagel SC, Sutovsky M, Sutovsky P, Sharpe-Timms KL. Neutralizing TIMP1 restores fecundity in a rat model of endometriosis and treating control rats with TIMP1 causes anomalies in ovarian function and embryo development. Biol Reprod. 2010;83(2):185-94.

48. Becher N, Hein M, Danielsen CC, Uldbjerg N. Matrix metalloproteinases in the cervical mucus plug in relation to gestational age, plug compartment, and preterm labor. Reprod Biol Endocrinol. 2010;8:113.

49. Tang LJ, De Seta F, Odreman F, Venge P, Piva C, Guaschino S, et al. Proteomic analysis of human cervical-vaginal fluids. J Proteome Res. 2007;6(7):2874-83.

50. Becker CM, Louis G, Exarhopoulos A, Mechsner S, Ebert AD, Zurakowski D, et al. Matrix metalloproteinases are elevated in the urine of patients with endometriosis. Fertil Steril. 2010;94(6):2343-6.

51. Watorek W. Azurocidin -inactive serine proteinase homolog acting as a multifunctional inflammatory mediator. Acta Biochim Pol. 2003;50(3):743-52.

52. Udby L, Sørensen OE, Pass J, Johnsen AH, Behrendt N, Borregaard N, et al. Cysteine-rich secretory protein 3 is a ligand of alpha1 B-glycoprotein in human plasma. Biochemistry. 2004;43(40):12877-86.

53. Burnett $L A$, Xiang $X$, Bieber AL, Chandler DE. Crisp proteins and sperm chemotaxis: discovery in amphibians and explorations in mammals. Int J Dev Biol. 2008;52(5-6):489-501.

54. Mairesse N, Bernaert D, Del Bino G, Horman S, Mosselmans R, Robaye B, et al. Expression of HSP27 results in increased sensitivity to tumor necrosis factor, etoposide, and $\mathrm{H}_{2} \mathrm{O}_{2}$ in an oxidative stress-resistant cell line. J Cell Physiol. 1998;177(4):606-17.

55. Iwabuchi T, Yoshimoto C, Shigetomi H, Kobayashi H. Oxidative stress and antioxidant defense in endometriosis and its malignant transformation. Oxid Med Cell Longev. 2015;2015:848595.

56. Goud PT, Goud AP, Joshi N, Puscheck E, Diamond MP, Abu-Soud HM. Dynamics of nitric oxide, altered follicular microenvironment, and oocyte quality in women with endometriosis. Fertil Steril. 2014;102(1):151-9.e5.

57. Yousef GM, Diamandis EP. The new human tissue kallikrein gene family: structure, function, and association to disease. Endocr Rev. 2001;22(2):184-204.

58. Petraki CD, Karavana VN, Diamandis EP. Human kallikrein 13 expression in normal tissues: an immunohistochemical study. J Histochem Cytochem. 2003;51(4):493-501.

59. Gerhard I, Roth B, Eggert-Kruse W, Runnebaum B. Effects of kallikrein on sperm motility, capillary tube test, and pregnancy rate in an $\mathrm{AlH}$ program. Arch Androl. 1990;24(2):129-45.

60. Adermann K, Wattler F, Wattler S, Heine G, Meyer M, Forssmann WG, et al. Structural and phylogenetic characterization of human SLURP-1, the first secreted mammalian member of the Ly-6/UPAR protein superfamily. Protein Sci. 1999;8:810-9.

61. Moriwaki Y, Yoshikawa K, Fukuda H, Fujii YX, Misawa H, Kawashima K. Immune system expression of SLURP-1 and SLURP-2, two endogenous nicotinic acetylcholine receptor ligands. Life Sci. 2007;80:2365-8.

62. Horiguchi K, Horiguchi S, Yamashita N, Irie K, Masuda J, Takano-Ohmuro $H$, et al. Expression of SLURP-1, an endogenous alpha7 nicotinic acetylcholine receptor allosteric ligand, in murine bronchial epithelial cells. J Neurosci Res. 2009;87:2740-7. 
63. Moriwaki Y, Watanabe Y, Shinagawa T, Kai M, Miyazawa M, Okuda T, et al. Primary sensory neuronal expression of SLURP-1, an endogenous nicotinic acetylcholine receptor ligand. Neurosci Res. 2009;64:403-12.

64. Mastrangeli R, Donini S, Kelton CA, He C, Bressan A, Milazzo F, et al. ARS component B: structural characterization, tissue expression and regulation of the gene and protein (SLURP-1) associated with Mal de Meleda. Eur J Dermatol. 2003;13:560-70.

65. Arredondo J, Chernyavsky Al, Grando SA. SLURP-1 and -2 in normal, immortalized and malignant oral keratinocytes. Life Sci. 2007;80:2243-7.

66. Swamynathan S, Buela KA, Kinchington P, Lathrop KL, Misawa H, Hendricks $\mathrm{RL}$, et al. Klf4 regulates the expression of Slurp1, which functions as an immunomodulatory peptide in the mouse cornea. Invest Ophthalmol Vis Sci. 2012;53(13):8433-46.

67. Swamynathan S, Swamynathan SK. SLURP-1 modulates corneal homeostasis by serving as a soluble scavenger of urokinase-type plasminogen activator. Invest Ophthalmol Vis Sci. 2014;55(10):6251-61.
68. Raggam RB, Wagner J, Prüller F, Grisold A, Leitner E, Zollner-Schwetz I, et al. Soluble urokinase plasminogen activator receptor predicts mortality in patients with systemic inflammatory response syndrome. J Intern Med. 2014;276(6):651-8.

69. Autilio C, Morelli R, Milardi D, Grande G, Marana R, Pontecorvi A, et al. Soluble urokinase-type plasminogen activator receptor as a putative marker of male accessory gland inflammation. Andrology. 2015;3(6):1054-61.

70. Dziarski R, Gupta D. Mammalian peptidoglycan recognition proteins (PGRPs) in innate immunity. Innate Immun. 2010;16(3):168-74.

71. Boutten A, Dehoux M, Edelman P, Seta N, Menard A, Madelenat P, Durand G. IL6 and acute phase plasma proteins in peritoneal fluid of women with endometriosis. Clin Chim Acta. 1992;210(3):187-95.

72. Allan G, Campen C, Hodgen G, Williams R, Charnock-Jones DS, Wan J, Erlander M, Palmer S. Identification of genes with differential regulation in primate endometrium during the proliferative and secretory phases of the cycle. Endocr Res. 2003;29(1):53-65.

73. Signorile PG, Baldi A. Supporting evidences for potential biomarkers of endometriosis detected in peripheral blood. Data Brief. 2015:5:971-4.

\section{Submit your next manuscript to BioMed Central and we will help you at every step:}

- We accept pre-submission inquiries

- Our selector tool helps you to find the most relevant journal

- We provide round the clock customer support

- Convenient online submission

- Thorough peer review

- Inclusion in PubMed and all major indexing services

- Maximum visibility for your research

Submit your manuscript at www.biomedcentral.com/submit 